\title{
LIBERTAD DE EXPRESIÓN, TERRORISMO Y LÍMITES DE LOS DERECHOS FUNDAMENTALES
}

POR

\author{
ANTONIO MAGDALENO ALEGRÍA \\ Profesor de Derecho Constitucional \\ Universidad de Cantabria
}

\section{INTRODUCCIÓN}

Que las libertades de expresión e información desempeñan un papel fundamental en los sistemas constitucionales y democráticos modernos es una cuestión que se encuentra fuera de toda duda. Del mismo modo, resulta mayoritariamente admitido que las citadas libertades públicas, como el resto de los derechos fundamentales, no son absolutas $y$, en consecuencia, son susceptibles de limitación con la finalidad de preservar otros derechos fundamentales o bienes constitucionalmente reconocidos. En este sentido, el Tribunal Constitucional, ya desde su inicial jurisprudencia, afirmó que «no existen derechos ilimitados. Todo derecho tiene sus límites, que, (...) con relación a los derechos fundamentales, establece la Constitución por sí misma en algunas ocasiones, mientras en otras el límite deriva de una manera mediata o indirecta de tal norma, en cuanto ha de justificarse por la necesidad de proteger o preservar no sólo otros derechos constitucionales, sino también otros bienes constitucionales protegidos ${ }^{1} "$.

${ }^{1}$ Véase STC 2/1982, de 29 de enero, FJ 5. ${ }^{\circ}$. Asimismo el Tribunal Constitucional también ha sostenido que: "tanto las normas de libertad como las llamadas normas 
A pesar de lo anterior, los contornos de los límites de las libertades de expresión e información continúan siendo una cuestión sumamente debatida pues se trata de un tema en el que no caben soluciones absolutas o definitivas. Prueba de ello es que la mayoría de los tribunales nacionales e internacionales, en sus numerosos pronunciamientos, acuden al método de ponderación casuística para la resolución de los conflictos entre las libertades de expresión e información y otros derechos o bienes constitucionales ${ }^{2}$.

En un primer momento, la doctrina científica de nuestro país se esforzó en la resolución de los conflictos entre las libertades de expresión e información y los derechos de la personalidad reconocidos en el artículo 18 de la Constitución, esto es, el derecho al honor, a la intimidad personal y familiar y la propia imagen ${ }^{3}$. Paulatinamente, los trabajos doctrinales se centraron en los denominados "otros límites" de las citadas libertades que son los límites derivados del contrato de trabajo, los límites específicos de los funcionarios o los límites derivados de la defensa y seguridad del Estado ${ }^{4}$.

limitadoras se integran en un único ordenamiento inspirado por los mismos principios en los que, en último término, resulta ficticia la contraposición entre el interés particular subyacente a las primeras y el interés público que, en ciertos supuestos, aconsejan su restricción. Antes al contrario, tanto los derechos individuales como sus limitaciones (...) son igualmente considerados por el artículo 10.1 de la Constitución como fundamento del orden público y de la paz social (...). Como resultado de esta interacción, la fuerza expansiva de todo derecho fundamental restringe, por su parte, el alcance de las normas limitadoras que actúan sobre el mismo; de ahí la exigencia de que los límites de los derechos fundamentales hayan de ser interpretados con criterios restrictivos y en el sentido más favorable, a la eficacia y a la esencia de tales derechos". Véanse STC 159/1986, de 12 de diciembre, FJ 6. ${ }^{\circ}$, STC 20/1990, de 15 de febrero, FJ $4 .^{\circ}$ y STC 81/1998, de 2 de abril, FJ $2 .^{\circ}$.

${ }^{2}$ Sobre el método de ponderación para la resolución de conflictos, entre otros, véanse PRIETO SANCHÍS, L.: "Observaciones sobre las antinomias y el criterio de ponderación", Cuadernos de Derecho Público, núm. 11, 2000, p. 9 y ss, SOLOZÁBAL ECHAVARRÍA, J.J.: "Los límites de los derechos fundamentales y el sistema normativo", Derecho Privado y Constitución, núm. 17, 2003, p. 449 y ss.

${ }^{3}$ Sobre la cuestión, entre otros, véanse, CARMONA SALGADO, C.: Libertad de expresión e información y sus límites, Edersa, Madrid, 1991, CARRILLO LÓPEZ, M.: Límites a la libertad de prensa en la Constitución de 1978, PPU, Barcelona, 1987, DESANTES GUANTER, J.M. y SORIA, C.: Los límites de la información, Asociación de la prensa de Madrid, Madrid, 1991.

${ }^{4} \mathrm{~A}$ modo de ejemplo, entre otros, véanse REBOLLO VARGAS, R.: "Los "otros" límites al ejercicio de los derechos a la libertad de expresión e información, buena fe, honor de la empresa y deber de lealtad al empresario", Cuadernos de Derecho Público, núm. 4, mayo-agosto, 1998, p. 241 y ss, ROJAS RIVERO, G.P.: Libertad de expresión del trabajador, Trotta, Madrid, 1991, CÁMARA VILLAR, G.: «Relaciones de 
Una de las cuestiones que ha generado mayor polémica entre la doctrina versa sobre la admisibilidad constitucional de limitar los discursos públicos que justifican la violencia terrorista por supuestas motivaciones políticas o incluso religiosas. El debate sobre la aludida cuestión se ha incrementado como consecuencia de dos medidas legislativas que tienen el objetivo de sancionar los discursos públicos que conviven con el terrorismo ${ }^{5}$. Se trata, de un lado, del artículo 578 del Código Penal, introducido mediante la LO 7/2000, de 22 de diciembre, por el que se castiga la justificación pública o enaltecimiento del terrorismo. De otro, la aprobación de la LO 6/2002 de Partidos Políticos (en adelante, LOPP) por la que cabe la posibilidad de proceder a la ilegalización de los partidos políticos cuyos dirigentes, representantes públicos, etc., realicen manifestaciones públicas de similares características.

El presente artículo tiene por objeto examinar la adecuación constitucional de las aludidas restricciones legislativas de la libertad de expresión. Como se adivina, se trata de una cuestión sumamente compleja y discutida. En consecuencia, resulta pertinente adoptar las máximas cautelas posibles para afrontar su análisis. Al objeto de examinar la constitucionalidad de las aludidas restricciones, en el presente estudio se acudirá fundamentalmente a tres parámetros distintos, que son: en primer lugar, la dimensión objetiva o institucional de las libertades de expresión e información reconocida en al jurisprudencia del Tribunal Constitucional. La aludida dimensión centra su atención en el papel esencial que desempeñan las libertades de expresión e información en Estado social y democrático de Derecho. En segundo lugar, se acudirá al Convenio Europeo de los Derechos Humanos (en adelante, CEDH o Convenio) y, consecuentemente, a la jurisprudencia del Tribunal Europeo de los Derechos Humanos (en adelante, TEDH) dado que

sujeción especial y derechos fundamentales", en APARICIO PÉREZ, M.A. (Coord.): Derechos constitucionales y formas políticas, Cedecs, Barcelona, 2001, p. 117 y ss, SOLOZÁBAL ECHAVARRÍA, J.J.: «Libertad de expresión, información y relaciones laborales", Revista Española de Derecho Constitucional, núm. 26, 1989, p. 165 y ss.

${ }^{5}$ Sobre la cuestión, entre otros, véanse ALÁEZ CORRAL, B.: "Libertad de expresión e ilegalización de partidos políticos", Repertorio Aranzadi del Tribunal Constitucional, núm. 15, 2002, p. 25 y ss, BERNAL DEL CASTILLO, J.: "Observaciones en torno a la Ley Orgánica 7/2000, de modificación del Código Penal en materia de terrorismo", La Ley, núm. 5, 2001, p. 1627 y ss, TORRES DEL MORAL, A.: "La inconstitucionalidad de los partidos políticos. A propósito de la Ley Orgánica 6/2002, de partidos políticos, Revista de Derecho Político, núm. 60, 2004, p. 41 y ss, VíRGALA FORURIA, E.: "Los partidos políticos tras la LO 6/2002", Teoría y Realidad Constitucional, núms. $10-11,2 .^{\circ}$ semestre $2002-11 .^{\circ}$ semestre 2003 , p. 203 y ss. 
en virtud del artículo 10.2 de la Constitución resulta un método de interpretación obligado para determinar el contenido y el alcance de las limitaciones de los derechos fundamentales reconocidos en la misma. Del mismo modo, y como se observará próximamente, la jurisprudencia del TEDH ha analizado supuestos relacionados con la justificación pública del terrorismo. Y, en tercer lugar, se acudirá a la teoría general de la limitación de los derechos fundamentales en el ordenamiento constitucional español. Este último instrumento de interpretación permitirá analizar el cumplimiento de los requisitos o garantías constitucionales para limitar los derechos fundamentales reconocidos en la Constitución española.

Tras exponer sintéticamente los instrumentos que se emplearán para examinar la legitimidad constitucional de los límites de las libertades de expresión e información, se aplicarán sobre las concretas restricciones, es decir, sobre el artículo 578 del Código Penal y la LOPP y, en consecuencia, se estará en la disposición de sostener una posición al respecto.

\section{LOS CRITERIOS PARA EXAMINAR LA LEGITIMIDAD CONSTITUCIONAL DE LAS RESTRICCIONES DE LAS LIBERTADES DE COMUNICACIÓN PÚBLICA}

\subsection{Algunas notas sobre el papel que desempeñan las libertades de comunicación pública en el Estado social y democrático de Derecho y la teoría institucional de los derechos fundamentales}

Resulta enormemente complejo sintetizar en unos breves párrafos algunas de las funciones que las libertades de expresión e información desempeñan en nuestra actual forma de Estado. Quizá, una fórmula idónea para alcanzar el citado objetivo consiste en apuntar sucintamente las trasformaciones de las libertades de expresión e información a lo largo de las distintas etapas por las que ha pasado el Estado y, en un momento posterior, enunciar su efectiva recepción jurisprudencial o constitucional a través de la teoría institucional.

En el Estado liberal, la libertad de expresión se concibió como un derecho de libertad sobre el que el Estado, en principio, no podía ejercer ningún tipo de impedimento. La necesidad de su protección se justificó, entre otras cuestiones, en que la libertad de expresión constituía un método para alcanzar la verdad, se erigía como un cauce pacífico para manifestar las discrepancias inherentes a toda sociedad plural y era un instrumento para ilustrar a la población en general. En este 
sentido, resultan enormemente esclarecedoras las siguientes palabras de JOHN MILTON: "todas las opiniones, incluso todos los errores, conocidos, leídos, comparados, son de especial provecho y ventajosos para el beneficio neto de la verdad más segura ${ }^{6} "$. En nuestro país, la exposición de motivos del Decreto IX de 10 de noviembre de 1810, sobre la libertad política de la imprenta, entre otros argumentos, fundamentó la necesidad del reconocimiento de la libertad de prensa en que ésta constituía un medio "de ilustrar la Nación en general", fruto del pensamiento ilustrado que atribuía muchos de los males de la sociedad a la ignorancia y a la falta de instrucción de los ciudadanos.

Con la llegada del Estado democrático, se advirtió la importancia de la libertad de prensa para el ejercicio del autogobierno de los ciudadanos. Concretamente, la prensa, al hacer públicos los asuntos generales y las ideas políticas, permite el control del poder político y fomenta el asociacionismo de los ciudadanos ${ }^{7}$. Del mismo modo, las libertades de expresión y de prensa son esenciales para el sistema representativo, dado que permiten a los electores conocer a los candidatos y elegirlos con fundamento. Sin embargo, a medida que avanza el Estado democrático, también se es consciente de algunos efectos negativos, destacándose que los medios de comunicación, que se encuentran en manos de los que dominan la estructura social, determinan qué cuestiones son debatidas y cómo han de llevarse a cabo tales controversias. Del mismo modo, la situación descrita genera que sólo unos pocos pueden expresarse de manera efectiva $y$, en consecuencia, se empobrece el debate público y se produce un funcionamiento deficitario del sistema democrático ${ }^{8}$.

${ }^{6}$ Véase MILTON, J.: Aeropagítica, Torres Goyanes, Madrid, 2001, p. 67.

7 En este sentido, ALEXIS DE TOCQUEVILLE mantuvo que: "en los países democráticos sucede a menudo (...) que un gran número de hombres que tienen el deseo o la necesidad de asociarse no pueden hacerlo porque, al ser todos muy pequeños y al estar perdidos en la multitud, no se ven y no saben donde encontrarse. Aparece el periódico que saca a la luz el sentimiento o la idea que se había presentado simultáneamente, pero por separado, a cada uno de ellos. Todos se dirigen enseguida hacia la luz, y esos espíritus errantes que se buscaban en las tinieblas desde hace mucho tiempo, se encuentran al fin y se reúnen". La prensa actúa como un medio donde todos pueden expresarse sin necesidad de estar reunidos, lo que le llevó a concluir que «no hay apenas asociación democrática que pueda pensarse sin un periódico". Véase DE TOCOUEVILLE, A.: La democracia en América, Aguilar, Madrid, 1989, p. 153

${ }^{8}$ Sobre la cuestión, y a modo de ejemplo, véase FISS, O.: «Free Speech and Social Structure», lowa Law Review, núm. 71, 1986, p. 1405 y ss. 
Esta última cuestión, tiene respuesta en el Estado social y democrático de Derecho pues los poderes públicos no sólo tienen la posibilidad sino el deber de corregir las circunstancias sociales que impiden el disfrute efectivo de los derechos fundamentales. En este sentido, las garantías de las libertades de expresión e información establecidas en la Constitución española son, en gran medida, reflejo de la evolución sintéticamente expuesta. Así, de un lado, la prohibición de censura previa o del secuestro administrativo son de clara influencia liberal, dado que persiguen proscribir los impedimentos gubernamentales a la libre difusión pública de ideas o informaciones. De otro, el derecho de acceso a los medios de comunicación públicos de los grupos sociales y políticos significativos o el control parlamentario de los mismos demuestran la asunción por parte de la Constitución de la nueva concepción de estas libertades en el Estado social y democrático de Derecho. Éstas últimas garantías, junto con el derecho de rectificación (de creación legislativa ${ }^{9}$ y los derechos de los profesionales de la información, tienen por objeto asegurar el efectivo ejercicio de estas libertades y amparar la libre formación de la opinión pública, cuestión imprescindible para el funcionamiento del Estado democrático.

El Tribunal Constitucional ha asumido, en un importante número de sus pronunciamientos, muchas de las cuestiones apuntadas precedentemente. Así, el Alto Tribunal español ha seguido los postulados de su homólogo alemán y ha reconocido que las libertades de expresión e información poseen una doble naturaleza, dado que, de un lado, son derechos subjetivos $y$, de otro, poseen una dimensión institucional. Más en concreto, el máximo interprete de la Constitución española mantiene que las libertades de comunicación pública no son sólo derechos individuales de cada ciudadano, sino que también significan el reconocimiento y garantía de una institución política fundamental, que es la opinión pública libre que, a su vez, está ligada indisolublemente al pluralismo político. En este sentido, la STC 127/1994, de 5 de mayo, sostiene que: "en diversas ocasiones hemos reiterado que los derechos de libre expresión e información, en su dimensión de derechos de libertad, significan básicamente la ausencia de interferencias o intromisiones en el proceso de comunicación, pero, a su vez, en su dimensión institucional, suponen una garantía de una opinión pública libre y del mantenimiento del pluralismo político ${ }^{10}$ ". En referencia a la dimensión institucional, la STC 156/1986, de 12 de diciembre, afirma que: "para

${ }^{9}$ Véase Ley Orgánica 2/1984, de 25 de marzo, reguladora del Derecho de rectificación.

${ }^{10}$ Véase STC 127/1994, de 5 de mayo, FJ 5.․ 
que un ciudadano pueda formar libremente sus opiniones y participar de modo responsable en los asuntos públicos, ha de ser informado ampliamente de modo que pueda ponderar opiniones diversas e incluso contrapuestas. En este sentido se ha manifestado este Tribunal (...) al poner reiteradamente de manifiesto que el derecho a la información no sólo protege un interés individual, sino que entraña el reconocimiento y garantía de una institución política fundamental, que es la opinión pública, indisolublemente ligada al pluralismo político ${ }^{11}$ ".

La vital importancia de las libertades de comunicación pública para el funcionamiento del Estado social y democrático de Derecho amparada por la dimensión institucional de dichas libertades, va a tener, entre otras, una importante consecuencia que se corresponde con su valor preponderante, que no preferente, frente a otros derechos fundamentales o bienes constitucionales ante un eventual conflicto. Sin embargo, no se trata de una preponderancia incondicionada o absoluta, sino que sólo se plasmará en el caso de que las opiniones manifestadas o las noticias transmitidas sean adecuadas al instituto constitucionalmente protegido en las mismas, es decir, en el supuesto de que sean necesarias para la formación de una opinión pública libre en una sociedad democrática ${ }^{12}$. Dicho de otro modo, la efectiva realización del instituto de la opinión pública es esencial para poder mantener la eventual preponderancia de las libertades de expresión e información frente a otros derechos fundamentales o bienes constitucionalmente reconocidos; se amparan en la medida que tiendan a la consecución del mencionado objetivo, que se considera imprescindible para el correcto funcionamiento del sistema democrático. Así, por ejemplo, la STC 171/1990, de 12 de noviembre, mantiene que el valor especial que la Constitución otorga a las libertades de expresión e información «no puede configurarse como absoluto, puesto que si viene reconocido como garantía de la opinión pública, solamente puede legitimar las intromisiones en otros derechos fundamentales que guarden congruencia con esa finalidad, es decir, que resulten relevantes para la

11 Véase STC 156/1986, de 12 de diciembre, FJ 6.․

12 Téngase en cuenta que la discutida doctrina de las libertades preferentes ha sido abandonada por la jurisprudencia del Tribunal Constitucional. Así, por ejemplo, la STC 11/2000, de 17 de enero, FJ 7.', afirma con rotundidad que: "nuestra jurisprudencia relativiza el valor preferente de las libertades de expresión e información, negándose su jerarquía sobre otros derechos fundamentales (...) y condicionando su protección constitucional a una ponderación». El citado criterio ha sido confirmado en la STC 158/2003, de 15 de septiembre, FJ 3. ${ }^{\circ}$, y en la STC 54/2004, de 15 de abril, FJ 3. . 
formación de la opinión pública sobre los asuntos de interés gene$\mathrm{ral}^{13}{ }^{\prime \prime}$.

\subsection{La limitación de las libertades de expresión e información en la jurisprudencia del Tribunal Europeo de los Derecho Humanos}

Precedentemente se ha aludido al papel del CEDH en la interpretación de los derechos fundamentales reconocidos en la Constitución española. En el presente punto se destacarán dos cuestiones sobre la jurisprudencia del TEDH, que son: de un lado, el valor de las libertades de expresión e información para el modelo de sociedad democrática protegido en el CEDH. De otro, al método utilizado por el Tribunal de Estrasburgo para determinar si una concreta restricción de la libertad de expresión es acorde con el propio CEDH.

Respecto de la primera cuestión, el TEDH ha hecho referencia constante en su jurisprudencia a que la libertad de expresión, entendida en el CEDH en sentido amplio, esto es, que comprende también la libertad de información, constituye uno de los elementos fundamentales de la democracia. Así, por ejemplo, el citado tribunal afirmó que "la libertad de expresión constituye uno de los pilares fundamentales de una sociedad democrática y una de las condiciones básicas para que ésta progrese y para el pleno desarrollo individual ${ }^{14} »$. En otra ocasión, el aludido tribunal mantuvo que "las elecciones libres y la libertad de expresión, especialmente la libertad de debate político, constituyen los cimientos de todo debate democrático ${ }^{15}$ ».

La cuestión apuntada tiene dos importantes consecuencias estrechamente relacionadas entre sí. En primer lugar, la función social que la libertad de expresión desempeña en el modelo de sociedad democrática protegido por el CEDH determina para el TEDH distintos grados de protección en el ejercicio de la misma. Así, por ejemplo, el debate político o las informaciones sobre cuestiones de interés general tienen un mayor nivel de protección en los conflictos con otros derechos o bienes protegidos que la publicidad comercial. En segundo lugar, y directamente relacionado con lo anterior, las restricciones impuestas sobre la libertad de expresión se deberán interpretar de forma restrictiva, sobre todo cuando su ejercicio esté directamente relacionado con el funcio-

${ }^{13}$ Véase STC 171/1990, de 12 de noviembre, FJ 5. ${ }^{\circ}$.

${ }^{14}$ A modo de ejemplo, véase STEDH de 27 de febrero de 2001, "caso Jerusalem", párr. 32.

15 Véase STEDH de 19 de febrero de 1998, "caso Bowman", párr. 42. 
namiento del sistema democrático. En consecuencia, como afirma reiteradamente el TEDH, no sólo son admisibles "las informaciones o ideas acogidas con favor o consideradas como inofensivas o indiferentes, sino también las que molestan, chocan o inquietan». Del mismo modo, el CEDH exige que la restricción de la libertad de expresión sea "necesaria para una sociedad democrática», es decir, la limitación debe ajustarse a las exigencias del modelo democrático preservado por el Convenio, que se caracteriza por el pluralismo, la tolerancia y el espíritu de apertura, lo que significa que toda formalidad, condición, restricción o sanción impuesta en la materia debe ser proporcional al objetivo legítimo que se persigue ${ }^{16}$.

En relación con la segunda cuestión, esto es, el CEDH como canon para enjuiciar la validez de las restricciones establecidas sobre los derechos reconocidos en el mismo, el TEDH desarrolló el denominado "test de Estrasburgo». El aludido test se aplica una vez constatada la injerencia o limitación por parte de las autoridades de un Estado sobre las libertades reconocidas en el Convenio, y consiste en los siguientes pasos: en primer lugar, se verifica que la limitación del derecho está prevista en la ley ${ }^{17}$. En segundo lugar, se comprueba que la injerencia

${ }^{16}$ A modo de ejemplo, véase STEDH de 7 de diciembre de 1976, caso Handyside, párr. 49.

${ }^{17}$ En relación con el requisito de la previsión legal de la limitación del derecho, el TEDH se ha mostrado más exigente en lo relativo a la calidad intrínseca de la norma, que en su naturaleza puramente formal. Es decir, se ha centrado más en la calidad de la norma que en su aspecto formal. Así, por ejemplo, la STEDH de 26 de abril de 1979, "caso The Sunday Times", párr. 47, examina la cuestión en referencia al ordenamiento jurídico británico y afirma que: «el Tribunal constata que la palabra "ley» en la expresión "prevista por la ley» engloba, a la vez, tanto el Derecho escrito (consuetudinario). Así no da importancia al hecho de que el "contempt of court" sea una creación de la "Common Law» y no de la legislación. Se iría manifiestamente contra la intención de los autores del Convenio si se dijese que una restricción impuesta por la "Common Law" no está "prevista por la ley" con el único motivo que no está enunciada en ningún texto legislativo: se privaría así a un Estado de "Common law», que forma parte del Convenio, de la protección del artículo 10.2 y se rompería la base del sistema jurídico".

Por ello, el TEDH sólo exige dos requisitos para considerar que la injerencia está prevista por la ley, que son: la accesibilidad y la previsibilidad de la ley. El primer requisito implica que "el ciudadano tiene que disponer patrones suficientes que se adecuen a las circunstancias de las normas legales aplicables al caso". La previsibilidad de la ley implica que "el derecho interno aplicable debe estar formulado con la precisión suficiente como para permitir que las personas afectadas - si es necesario con la asesoría pertinente- prever, hasta un grado razonable en las circunstancias del caso, las consecuencias que pueden resultar de un acto determinado". 
se encuentra justificada en la consecución de alguno de los fines que legitiman la restricción de un determinado derecho protegido en el CEDH. $Y$, finalmente, se examina si la restricción es necesaria para una sociedad democrática. A su vez, este último requisito se compone de dos aspectos esencialmente, que son: la necesidad de la injerencia y su proporcionalidad. Respecto del primer aspecto, el TEDH ha manifestado que el adjetivo necesario no es sinónimo de indispensable, pero tampoco puede ser interpretado en términos tan amplios como, por ejemplo, "útil», "normal», "razonable» u "oportuno"18". El TEDH ha establecido que este requisito se identifica con una "necesidad social imperiosa en el contexto de una sociedad democrática" caracterizada por el pluralismo, la tolerancia y un espíritu abierto ${ }^{19}$. El segundo aspecto o requisito implica que las decisiones de las autoridades nacionales que limiten el ejercicio de un derecho reconocido en el CEDH han de estar fundamentadas en una aceptable valoración de los hechos relevantes, de modo que se haya mantenido un justo equilibrio entre el derecho fundamental del individuo sometido a restricción y el interés legítimo perseguido por un Estado democrático al imponer tal restricción ${ }^{20}$.

\subsection{Los límites de los límites de los derechos fundamentales}

Como se ha recordado en la introducción del presente estudio, los derechos fundamentales no son absolutos $y$, por ende, pueden ser sometidos a restricciones. A su vez, la posibilidad de limitar los derechos fundamentales también se encuentra restringida, puesto que necesitará de una norma de habilitación o autorización constitucional. Asimismo, la restricción del derecho deberá estar justificada en la protección de otro derecho o bien constitucional. Y, por último, el límite deberá cumplir las distintas exigencias o requisitos constitucionales que pretenden asegurar la vinculación del legislador a los derechos funda-

Véanse STEDH de 26 de abril de 1979, "caso Sunday Times», párr. 39 y STEDH de 27 de marzo de 1996, "caso Goodwin", párr. 31.

${ }^{18}$ Véase STEDH de 7 de diciembre de 1976, "caso Handyside", párr. 48.

${ }^{19}$ Este criterio se inició en la ya citada STEDH de 26 de abril de 1979, "caso Sunday Times", párr. 62, y continua siendo totalmente vigente, como se observa en la STEDH de 10 de junio de 2003, "caso Cumpana y Mazare», párr. 46.

${ }^{20}$ Véase GARCÍA SAN JOSÉ, D.I.: Los derechos y libertades fundamentales en la sociedad europea del siglo XXI, análisis de la interpretación y aplicación por el Tribunal Europeo de los Derecho Humanos de la cláusula "necesario para una sociedad democrática", Universidad de Sevilla, Sevilla, 2001, p. 75. 
mentales, es decir, el legislador deberá respetar a la hora de restringir un determinado derecho fundamental "los límites de los límites». Concretamente, con la expresión "límites de los límites de los derechos fundamentales" se hace referencia al "conjunto de institutos que, en cuanto requisitos formales y materiales para las leyes restrictivas de los derechos y de las libertades, operan a modo de límites de la capacidad del legislador en dicha materia ${ }^{21} "$. Los límites de los límites junto con los conceptos de contenido y límites constituyen la tríada necesaria por medio de la cual se expresa la vinculación del legislador a los derechos fundamentales ${ }^{22}$.

Pues bien, en el presente momento se enunciarán de manera muy breve estos últimos y, en los posteriores epígrafes, se emplearán para determinar la adecuación constitucional de las concretas limitaciones de la libertad de expresión.

1.3.1. La reserva de ley en la limitación de los derechos fundamentales

Siguiendo el camino predispuesto, para que una limitación de un derecho fundamental se ajuste a nuestra norma fundamental se deberá realizar mediante una ley que, a su vez, deberá ser proporcional y que, además, deberá respetar el contenido esencial del derecho sometido a restricción.

La necesidad de una ley para limitar un derecho fundamental, establecida por el artículo 53.1 de la Constitución, es una garantía de carácter formal que no prejuzga el contenido de la norma legislativa, sino que tiene como objetivo establecer la obligación de que la decisión sea legislativa. Sobre esta cuestión, el Tribunal Constitucional ha afirmado que el "principio de reserva de ley entraña, en efecto, una garantía esencial de nuestro Estado de Derecho, y como tal ha de ser preservado. Su significado último es el de asegurar que la regulación de los ámbitos de libertad que corresponden a los ciudadanos dependa exclusivamente de la voluntad de sus representantes, por lo que tales ámbitos han de quedar exentos de la acción del ejecutivo y, en consecuencia, de sus productos normativos propios, que son los reglamentos ${ }^{23}$ ".

${ }^{21}$ Véase AGUIAR DE LUQUE, L.: "Los límites de los derechos fundamentales", Revista del Centro de Estudios Constitucionales, núm. 14, 1993, p. 25.

${ }^{22}$ Véase MARTÍN-RETORTILLO, L. y DE OTTO Y PARDO, I.: Derechos fundamentales y Constitución, Civitas, Madrid, 1988, p. 126.

${ }^{23}$ Véase STC 83/1984, de 24 de julio, FJ $4 .^{\circ}$. 


\subsubsection{El principio o test de proporcionalidad}

Hay un buen número de autores que han formulado un importante número de objeciones a la vigencia del principio de proporcionalidad en nuestro ordenamiento constitucional ${ }^{24}$. Sin embargo, el aludido principio ha sido objeto de recepción por parte del Tribunal Constitucional y ha fundamentado su existencia en que éste es un elemento integrante del Estado de Derecho ${ }^{25}$.

El principio de proporcionalidad se compone de tres subprincipios o elementos, que son: el principio de adecuación o idoneidad, el principio de necesidad y el principio de proporcionalidad en sentido estricto. EI uso de los citados subprincipios se realiza de manera escalonada, lo que implica que si en la aplicación de cualquiera de estos subprincipios se considera que la medida de que se trate no supera el test correspondiente, podrá detenerse ya el examen y rechazar la medida por ser inconstitucional.

El primer subprincipio del test de proporcionalidad es el principio de idoneidad. Mediante este subprincipio se trata de determinar la aptitud de la medida objeto de control, esto es, el límite, para conseguir la finalidad perseguida, es decir, la protección de otro derecho o bien constitucional. El requisito de la idoneidad no implica que la medida objeto de control deba ser el mejor instrumento para la consecución de la finalidad perseguida, sino que, por el contrario, se observará su vigencia siempre que dicha medida contribuya a acercar la consecución de la finalidad perseguida. En consecuencia, como afirma el Tribunal Constitucional, sólo serán desechadas las limitaciones legislativas de los derechos fundamentales que sean plenamente inadecuadas para alcanzar la finalidad perseguida con la misma ${ }^{26}$. El juicio de idoneidad se efectuará ex ante, es decir, no se realizará a partir de las consecuencias reales de la medida controlada, sino desde la perspectiva de la situación existente en el momento de adoptar la decisión de limitar el derecho fundamental.

El segundo subprincipio, que es el test de necesidad, consiste en constatar la ausencia de restricciones menos gravosas para la consecución, con igual eficacia, de la finalidad perseguida ${ }^{27}$. Dicho en otros términos, para superar el test de necesidad se deberá demostrar que no

${ }^{24}$ Sobre la cuestión, véase JIMÉNEZ CAMPO, J.: Los derechos fundamentales. Concepto y garantía, Trotta, Valladolid, 1999, p. 67 y ss.

${ }^{25}$ Véase STC 85/1992, de 18 de julio, FJ $4 .^{\circ}$.

${ }^{26}$ Véase STC 55/1996, de 28 de marzo, FJ 7.. 
existe un medio menos restrictivo para preservar un determinado derecho o bien constitucional. El juicio de idoneidad se centra en las posibles alternativas existentes para alcanzar un mismo fin, de lo que se deduce que: "la necesidad de la medida de control no es absoluta, sino relativa, en el sentido de que se requiere que no exista una alternativa menos gravosa y de igual eficacia para dar alcance a su finali$\operatorname{dad}^{28}$ ". De todos los modos, el Tribunal Constitucional ha limitado su propio ámbito de control respecto a este subprincipio ${ }^{29}$. En consecuencia, sólo será declarada la desproporcionalidad de una medida «si a la luz del razonamiento lógico, de datos empíricos no controvertidos y del conjunto de sanciones que el mismo legislador ha estimado necesarias para alcanzar fines de protección análogos, resulta evidente la manifiesta suficiencia de un medio alternativo menos restrictivo de derechos para la consecución igualmente eficaz de las finalidades deseadas por el legislador, podría procederse a la expulsión de la norma del ordenamiento" ${ }^{30} "$.

Por último, el principio de proporcionalidad en sentido estricto consiste en el examen de la existencia de una relación razonable o proporcionada entre los medios utilizados y el fin perseguido. Como afirma BRAGE CAMAZANO, según el principio de proporcionalidad en sentido estricto "deben ponderarse materialmente las ventajas e inconvenientes que se derivarían de la intervención de que se trate (medio) en el derecho fundamental para determinar si las ventajas que lleva consigo para el bien público (fin perseguido) tienen un peso específico suficiente para justificarla ${ }^{31}$ ». Esto implica que hay que sopesar "en los dos

\footnotetext{
27 Véase STC 55/1996, de 28 de marzo, FJ 8..

28 Véase GONZÁLEZ BEILFUSS, M.: El principio de proporcionalidad en la jurisprudencia del Tribunal Constitucional, Aranzadi, Cizur Menor, 2003, p. 129.

${ }^{29}$ En este sentido, la STC 136/1999, de 20 de julio, FJ 27. ${ }^{\circ}$, mantiene que: «el control del Tribunal Constitucional sobre "la existencia o no de medidas alternativas menos gravosas pero de la misma eficacia [...] tiene un alcance y una intensidad muy limitadas, so pena de arrogarse un papel de legislador imaginario que no le corresponde y de verse abocado a realizar las correspondientes consideraciones políticas, económicas y de oportunidad que le son institucionalmente ajenas y para las que no está constitucionalmente concebido"; por ello, esta tacha de desproporción solamente será aplicable cuando "las medidas alternativas (sean) palmariamente de menor intensidad coactiva y de una funcionalidad manifiestamente similar a la que se critique por desproporcionada"n.

30 Véanse STC 66/1996, de 8 de mayo, FJ 8. ${ }^{\circ}$ y STC 136/1999, de 20 de julio, FJ 23. .

31 Véase BRAGE CAMAZANO, J.: Los límites a los derechos fundamentales, Dykinson, Madrid, 2004, p. 380.
} 
platillos de la balanza, las ventajas que se derivarían para los afectados si no se produjese la intervención en su derecho fundamental respecto de los inconvenientes que se derivarían para el bien público si tal intervención no se produjese, así como las ventajas que conlleva la intervención en el derecho para el bien público frente a los inconvenientes que tiene para los afectados, de tal manera que cuanto mayor, más grave, intensa o pesada sea la intervención en los derechos fundamentales de los afectados, tanto más grave ha de ser la afectación del interés público que se produciría de no mediar la intervención de que se trate en el derecho fundamental ${ }^{32}$ ». En este sentido, la jurisprudencia constitucional mantiene que este principio consiste en que la medida enjuiciada sea proporcionada por derivarse «más beneficios o ventajas para el interés general que perjuicios sobre otros bienes o valores en conflicto ${ }^{33}$ ".

\subsubsection{El contenido esencial de los derechos fundamentales}

El último límite de los límites de los derechos fundamentales, tal y como establece el artículo 53.1 de la Constitución, es el respeto al contenido esencial del derecho sometido a restricción. En consecuencia, una vez que se haya acreditado la justificación de la limitación de un determinado derecho y la adecuación, necesidad y proporcionalidad en sentido estricto de la misma, se deberá comprobar, en última instancia, que la limitación no vulnere el contenido esencial del derecho sometido a restricción. En este sentido, y como afirma PRIETO SANCHÍS, el contenido esencial constituye la última trinchera de protección de los derechos fundamentales y de las libertades públicas ${ }^{34}$.

Como mantiene el Tribunal Constitucional, se entiende por contenido esencial «aquella parte del contenido de un derecho sin la cual éste pierde su peculiaridad o, dicho de otro modo, lo que hace que sea reconocible como derecho perteneciente a un determinado tipo. Es también aquella parte del contenido que es ineludiblemente necesaria para que el derecho permita dar a su titular la satisfacción de aquellos intereses para cuya protección el derecho se otorga ${ }^{35}$ ".

32 Véase BRAGE CAMAZANO, J.: Los límites a los derechos fundamentales, ob. cit., p. 380.

${ }^{33}$ Véanse, entre otras, STC 66/1995, de 8 de mayo, FJ 5. ${ }^{\circ}$, STC 55/1996, de 28 de marzo, FJ $7 .^{\circ}, 8 .^{\circ}$ y $9 .^{\circ}$, STC 186/2000, de 10 de julio, FJ 6. ${ }^{\circ}$.

${ }^{34}$ Véase PRIETO SANCHÍS, L.: Estudios sobre los derechos fundamentales, Debate, Madrid, 1990, p. 147.

${ }^{35}$ Véase STC 11/1981, 8 de abril, FJ 10.․ 
Existe una gran dificultad para determinar el contenido esencial de un determinado derecho fundamental. Hasta tal punto llega la aludida dificultad que sólo se conoce una definición del contenido esencial de la libertad de expresión que se corresponde con el derecho a discrepar razonadamente ${ }^{36}$.

\section{LOS LÍMITES DE LA LIBERTAD DE EXPRESIÓN DERIVADOS DE LA DEFENSA DEL ESTADO DEMOCRÁTICO Y DE LA PAZ SOCIAL}

\subsection{La justificación o enaltecimiento del terrorismo en el Código Penal}

El artículo 578 del Código Penal, introducido mediante la LO 7/2000, de 22 de diciembre, dispone que: «el enaltecimiento o la justificación por cualquier medio de expresión pública o difusión de los delitos comprendidos en los artículos 571 a 577 de este Código o de quienes hayan participado en su ejecución, o la realización de actos que entrañen descrédito, menosprecio o humillación de las víctimas de los delitos terroristas o de sus familiares se castigará con la pena de prisión de uno a dos años». Como se observa, este precepto penal determina dos conductas típicas claramente diferenciadas. De un lado, el enaltecimiento o justificación por cualquier medio de expresión público de los delitos terroristas o de los que hayan participado en su ejecución. Y, de otro, el menosprecio o la humillación de las víctimas de los delitos terroristas o de sus familiares. El presente estudio sólo se ceñirá al primero de los dos supuestos apuntados.

Con relación a este tipo penal se pueden destacar varias cuestiones. En primer lugar, el artículo 578 del Código penal castiga dos conductas, que son: de un lado, el enaltecimiento $y$, de otro, la justificación del terrorismo. El enaltecimiento, según el diccionario de la RAE, es sinónimo de ensalzar. A su vez, ensalzar significa exaltar, engrandecer, elogiar o alabar. Respecto de la segunda expresión, justificar significa probar una cosa con razones convincentes, testigos o documentos $\mathrm{y}$, también, rectificar o hacer una cosa justa. En segundo lugar, este delito sólo penaliza los mensajes de justificación o exaltación de las acciones terroristas que se difundan de manera pública, por tanto, no se castigan las manifestaciones meramente privadas. En tercer lugar, para la aplicación de este delito, en principio no se exige la concurrencia de ningún

${ }^{36}$ Véase VIVES ANTÓN, T.S.: La libertad como pretexto, Tirant lo Blanch, 1995, p. 371. 
requisito adicional a la expresión pública de este tipo de mensajes. Esto significa que no es necesario que las expresiones que se describen en el artículo 578 del Código Penal inciten directamente a la comisión de delitos terroristas y, por tanto, el legislador orgánico se ha separado del clear and present danger test elaborado por el Tribunal Supremo de los Estados Unidos ${ }^{37}$. Y, en cuarto lugar, el artículo 578 no es un delito de terrorismo, sino de expresión, esto es, no puede ser considerado un acto terrorista aunque el legislador así lo ha establecido al encuadrar el citado artículo bajo la rúbrica "de los delitos de terrorismo ${ }^{38}$ ".

Muchas han sido las dudas doctrinales sobre la compatibilidad de este precepto penal con la libertad de expresión reconocida en la Constitución, en consecuencia, en el presente epígrafe se tratará de enjuiciar su idoneidad constitucional desde las premisas enunciadas precedentemente.

Así, en primer lugar, se analizará el artículo 578 desde la dimensión institucional de la libertad de expresión, más en concreto, desde la perspectiva del instituto protegido por la libertad de expresión que se corresponde con la libre formación de la opinión pública. Como se dijo en su momento, la especial consideración y potencial preponderancia de las libertades de expresión e información frente a otros derechos y bienes constitucionales procede de la dimensión institucional o social de las primeras, esto es, de las funciones que desempeñan las citadas libertades del Estado social y democrático de Derecho. Pues bien, en el presente estudio se considera que las expresiones de justificación o exaltación de la violencia terrorista no contribuyen en nada a formar libremente la opinión pública, sino más bien todo lo contrario ${ }^{39}$. La realidad ha demostrado que este tipo de mensajes no pretenden introducir en el libre mercado de las ideas una cuestión de interés público para su libre discusión, sino lo que verdaderamente buscan es po-

${ }^{37}$ Sobre el clear and present danger test, véase 249 U.S 47 (1919), 249 U.S 211 (1919) y 250 U.S 616 (1919).

${ }^{38}$ En este sentido, véase ATS de 23 de mayo de 2002. Doctrinalmente véase COBO DEL ROSAL, M.: "Sobre la apología criminal y los delitos de terrorismo», Cuadernos de Política Criminal, núm. 76, 2002, p. 116.

${ }^{39}$ En el mismo sentido, RUIZ LANDÁBURU afirma lo siguiente: “¿En qué medida la alabanza al delito es un elemento relevante para la formación de una opinión pública libre y democrática? ¿en qué medida escuchar esos mensajes nos hace participar en los asuntos públicos de forma responsable? En nada. Al contrario, muchas veces la coarta, aunque eso sí, la de los demás. Es más: aunque para algunos no parezca estar muy claro, el crimen no es una opción válida en una sociedad democrática. Precisamente por eso se sanciona». Véase RUIZ LANDÁBURU, M.J.: Provocación y apología: delitos de terrorismo, Colex, Madrid, 2002, p. 79. 
tenciar los efectos y los objetivos de los atentados terroristas en la sociedad, es decir, tratan de favorecer una estrategia de intimidación e imposición por la violencia de unos objetivos de carácter político. Estos mensajes tienden más a producir una acción dañina que un mayor grado de debate y, por tanto, socavan el funcionamiento pacífico del mercado de las ideas. En consecuencia, se considera que, de un lado, este tipo de mensajes carecen de la especial protección que otorga la dimensión institucional de la libertad de expresión. Y de otro, es necesaria su limitación precisamente con el objeto de proteger el instituto amparado por la libertad de expresión que se corresponde con la libre formación de la opinión pública. Esta parece ser la posición de la STC 136/1999, de 20 de julio, pues afirma que: «no cabe considerar ejercicio legítimo de las libertades de expresión e información a los mensajes que incorporen amenazas o intimidaciones a los ciudadanos o a los electores, ya que con ellos ni se respeta la libertad de los demás, ni se contribuye a una formación de la opinión pública que se merezca el calificativo de libre ${ }^{40}$ ».

En mi opinión, este tipo de expresiones destruyen la dinámica del autogobierno de los ciudadanos a través de la libre discusión, precisamente porque pretenden que la discusión deje de ser libre al realizar una exaltación o justificación del terrorismo que amenaza constantemente a la vida y la seguridad de las personas. Para que un debate público sea verdaderamente libre debe realizarse respetando una serie de normas que aseguren que éste sea racional. En un Estado social y democrático de Derecho no sólo se deben asegurar el derecho a disentir de la mayoría, sino también se tienen que garantizar las condiciones sociales en las que las libertades de expresión e información puedan ser ejercidas libre y efectivamente por todos los ciudadanos. Así, siguiendo la doctrina del efecto silenciador de la libertad de expresión desarrollada por el profesor FISS, no se teme que las expresiones de exaltación o amparo del terrorismo (que constituyen una clase de expresiones de odio) lleguen a convencer a los oyentes de realizar las mismas actividades, sino que este tipo de expresiones disuadan a quienes son víctimas de las mismas de participar en la discusión pública ante el temor

${ }^{40}$ Véase STC 136/1999, de 20 de julio, FJ 15. ${ }^{\circ}$. La citada sentencia en el FJ $16 .^{\circ}$ incide en esta idea y afirma que: "no puede negarse la posibilidad de que existan mensajes que, aun sin hallarse incursos en alguno de los tipos penales de amenazas o coacciones, puedan considerarse intimidatorios, porque anuden, explícita o implícitamente, pero de modo creíble, la producción de algún mal grave o la realización o no realización de determinada conducta por parte del destinatario. Este tipo de mensajes no queda amparado por las libertades de expresión o de información». 
de ser objetivos de estas acciones ${ }^{41}$. Cuando el Estado restringe este tipo de expresiones, lo hace con el objeto de incrementar el grado de debate, procura el ejercicio efectivo de los derechos fundamentales, pues, precisamente una de las principales tareas del Estado social y democrático de Derecho consiste en promover las condiciones que aseguren el ejercicio real y efectivo de los derechos fundamentales por parte del individuo y de los grupos en que se integra. Lo anterior implica que el Estado tiene que evitar los mensajes de contenido amenazante o justificadores de la violencia con el objeto de que los demás puedan ejercer libremente sus derechos, esto es, con el fin de evitar su efecto silenciador y el falseamiento del sistema democrático. De igual manera, las expresiones de justificación o exaltación de los medios y acciones terroristas no se ajustan a otra importante función social de la libertad de expresión que reside en constituir un cauce pacífico para manifestar las divergencias de carácter político o de cualquier otra índole ${ }^{42}$. Como se ha aludido precedentemente, ya desde el reconocimiento de la libertad de expresión en el Estado liberal, una de las principales características de la citada libertad residía en constituir un marco donde se canalizaban las disputas y divergencias inherentes a toda sociedad plural de modo pacífico y, consecuentemente, sin el recurso al uso de la violencia.

En segundo lugar, para analizar la constitucionalidad del artículo 578 del Código penal se acudirá a la jurisprudencia del TEDH. Pues bien, el TEDH respecto a los discursos de incitación, justificación o elogio del recurso a la violencia para la consecución de fines políticos sostiene claramente que no se encuentran amparados por la libertad de expresión ${ }^{43}$. Esta posición la mantiene alegando que precisamente, una de p. 28.

${ }^{41}$ Véase FISS, O.: La ironía de la libertad de expresión, Gidesa, Barcelona, 1999,

${ }^{42}$ En este sentido, ULRICH PIEPER mantiene que "la violencia como medio de confrontación tanto en el campo político como en los ámbitos privados y sociales aparece como una forma arcaica de enfrentamiento. El desarrollo del derecho y de la Constitución como medios para la resolución de conflictos es un particular logro cultural, que responde a la necesidad básica del individuo de seguridad y protección y que garantiza en buena parte la libertad de acción". Véase ULRICH PIEPER, S.: "Partidos políticos y apología de la violencia», Persona y Derecho, núm. 44, 2001, p. 311.

${ }^{43}$ Del mismo modo, el TEDH entiende que: "las expresiones que tienden a propagar, incitar o justificar el odio basado en la intolerancia, incluida la intolerancia religiosa, no se benefician de la protección del artículo 10 del Convenio". Véase STEDH de 4 de diciembre de 2003, "caso Müslüm Gündüz", párr. 51. La posición enunciada, ha sido criticada con severidad por el juez Bonello. Véase voto particular formulado a la STEDH de 8 de julio de 1999, "Caso Arslan". 
las principales características de la democracia reside en la posibilidad que ésta ofrece de resolver desde el diálogo y sin recurrir a la violencia los problemas con que se encuentra un país. La democracia se nutre de la libertad de expresión ${ }^{44}$.

Lo anterior tiene como consecuencia que el canon de ponderación que emplea el TEDH a la restricción de este tipo de mensajes es distinto al que se aplica al discurso político. Así, en el ámbito de la crítica o discusión política el TEDH interpreta más restrictivamente los límites de la libertad de expresión, incluso suele llegar a amparar los mensajes que contienen una cierta virulencia o crítica gratuita en la discusión política ${ }^{45}$. En este sentido, el TEDH recuerda en numerosas ocasiones que «el artículo 10.2 del Convenio no deja apenas lugar a las restricciones a la libertad de expresión en el ámbito del discurso político o de las cuestiones de interés general ${ }^{46}$ ").

Por el contrario, cuando un individuo incita o justifica públicamente la utilización de la violencia para conseguir objetivos políticos o incluso religiosos, desaparece esa especial protección y, por tanto, cobran fuerza o peso los fines que justifican su limitación. Por ello, para aplicar un canon u otro de ponderación, el TEDH analiza si las expresiones que se manifiestan públicamente justifican o amparan los métodos violentos o terroristas ${ }^{47}$. En el caso de que se justifique la violencia, el TEDH ponderará la necesidad de la limitación de la libertad de expresión «a la luz del conjunto del asunto, incluido el contenido de las palabras reprochadas al demandante y el contexto en el que se pronunciaron ${ }^{48}$ ".

${ }^{44}$ Véase STEDH de 30 de enero de 1998, "caso Partido Unificado de Turquía", párr. 57. Asimismo, entre otras, véanse STEDH de 25 de mayo de 1998. "caso Partido Socialista de Turquía", párr. 45, STEDH de 9 de abril de 2002, "caso Yazar", párr. 48, STEDH de 2 de octubre de 2001, "caso Stankov y la Organización Macedonia Unida llinden", párr. 88, STEDH de 8 de diciembre de 1999, "caso Partido de la Libertad", párr. 44.

${ }^{45}$ A modo de ejemplo, véase STEDH de 9 de marzo de 2004, "caso Abdullah Aydin", párr. 31.

${ }^{46}$ En este sentido, entre otras, véanse STEDH de 8 de julio de 1986, "caso Ligens", párr. 42, STEDH de 23 de abril de 1992, "caso Castells", párr. 43, STEDH de 25 de noviembre de 1996, "caso Wingrove", párr. 58.

${ }^{47}$ Sobre la cuestión, entre otras, véanse STEDH de 8 de julio de 1999, "caso Sürek», párr. 62, STEDH de 28 de septiembre de 1999, "caso Öztürk», párr. 68, STEDH de 15 de octubre 2002, "caso Karakoç", párr. 43, STEDH de 9 de marzo de 2004, "caso Abdullah Aydin", párr. 31 y ss, STEDH de 23 de septiembre de 2004, "caso Feridun Yazar", párr. 27.

${ }^{48}$ Véase STEDH de 25 de noviembre de 1997, "caso Zana», párr. 51. 
Respecto del contexto en el que se realizan este tipo de expresiones, el TEDH tiene en cuenta la efectiva existencia de la violencia terrorista en el lugar donde se emitieron públicamente y las posibles repercusiones en el mismo. Así, por ejemplo, en la STEDH de 25 de noviembre de 1997, "caso Zana", que trata sobre un dirigente político que afirmó que "apoyaba el movimiento de liberación nacional del PKK», el TEDH entendió que la «declaración no puede, (...), considerarse aisladamente. Dadas las circunstancias del caso tuvieron una gran repercusión que el demandante no podía ignorar. Tal y como el Tribunal señaló anteriormente (...), la entrevista coincidió con atentados mortales perpetrados por el PKK contra civiles en el sudeste de Turquía, lugar donde reinaba, en el momento de los hechos, una tensión extrema. En estas circunstancias, el apoyo al PKK, calificado de «movimiento de liberación nacional», por parte del antiguo alcalde de Diyarbakir, la ciudad más importante del sudeste de Turquía, en una entrevista publicada en un gran periódico nacional, podría agravar una situación ya de por sí explosiva en esa región ${ }^{49}$ ".

En los contextos como el descrito, el TEDH amplía el margen de apreciación de las autoridades de los Estados contratantes del Convenio para valorar la necesidad de limitar los derechos reconocidos en el mismo porque están en mejor disposición de evaluarlo. Dicho en palabras del propio Tribunal, "allí donde las declaraciones litigiosas incitan al uso de la violencia con respecto a un individuo, un representante del Estado o una parte de la población, las autoridades nacionales gozan de un margen de apreciación más amplio en su examen

49 Véase STEDH de 25 de noviembre de 1997, "caso Zana», párr. 59 y 60. Este criterio también fue seguido en la STEDH de 8 de julio de 1999, "caso Sürek». El citado caso versa sobre la publicación en un periódico de unas cartas en las que se realiza una llamada a la venganza sangrienta contra las autoridades turcas. Concretamente, cuando el TEDH realiza la ponderación entre la libertad de expresión y el bien jurídico que justifica su restricción, afirma que: «conviene (...) tener en cuenta la situación reinante en materia de seguridad en el sudeste de Turquía cuando se publicaron las cartas: aproximadamente desde 1985, graves disturbios causaban estragos entre las fuerzas de seguridad y los miembros del PKK y habían supuesto enormes pérdidas humanas y la proclamación del estado de emergencia en la mayor parte de la región (...). En este contexto, es preciso recordar que el contenido de las cartas era susceptible de favorecer la violencia en la región, insuflando un odio irracional contra los que eran presentados como responsables de las atrocidades que alegaban. De hecho, el lector saca la impresión de que el recurso a la violencia es una medida de autodefensa necesaria y justificada de cara al agresor. Véase STEDH de 8 de julio de 1999, "caso Sürek», párr. 62. 
de la necesidad de la injerencia en el ejercicio de la libertad de expresión ${ }^{50}$ ".

En resumen, según el TEDH, las expresiones de incitación o justificación pública del terrorismo o del uso de la violencia, como norma general, no pueden ser protegidas por el artículo 10 del Convenio, dado que estas expresiones no cumplen las funciones de la libertad de expresión en el modelo de democracia protegido en el mismo. En cualquier caso, el citado tribunal siempre realizará una ponderación en la que tratará de determinar, vistas las circunstancias del caso concreto, la necesidad de la restricción de la libertad de expresión. En la citada ponderación cobra especial protagonismo la efectiva existencia de la violencia terrorista en el lugar donde se emiten este tipo de expresiones y/o la posibilidad de que las expresiones generen disturbios o incrementen la tensión, de tal forma que de darse efectivamente, la restricción normalmente se estimará conforme al Convenio.

En tercer lugar, se examinará el artículo 578 desde la perspectiva de la teoría general de la limitación de los derechos fundamentales. Como se recordará, cualquier limitación de un derecho fundamental reconocido en la Constitución se deberá justificar en la protección de otros derechos o bienes constitucionalmente reconocidos mediante una ley proporcional que, a su vez, deberá respetar el núcleo esencial del derecho sometido a limitación.

Respecto de la necesidad de justificación, el legislador posee un importante grado de libertad a la hora de determinar los derechos y bienes susceptibles de limitar los derechos fundamentales con el objeto de armonizarlos y, por tanto, hacerlos reales y efectivos. El legislador se encuentra en la mejor posición para apreciar la necesidad de limitar determinados derechos con el objeto de proteger otros derechos y bienes desde sus coordenadas ideológicas y valorando las necesidades de la sociedad en cada momento, cuestión que se deriva de su posición constitucional $y$, en última instancia, de su específica legitimidad democrática. Pues bien, el legislador orgánico ha determinado de manera implícita que el fundamento de la citada restricción reside en la salvaguardia de la paz social, la lucha contra el terrorismo, y en definitiva, de la protección del funcionamiento del sistema democrático ${ }^{51}$. Consi-

50 Véase STEDH de 7 de febrero de 2002, "caso E.K», párr. 70. Asimismo, entre otras, véanse STEDH de 28 de septiembre de 1999, "caso Öztürk», párr. 66, STEDH de 8 de julio de 1999, "caso Arslan", párr. 46.

51 En este sentido, GAVARA DE CARA mantiene que no es necesario que la finalidad de la limitación sea explicitada por el legislador, "es suficiente que la finali- 
dera que las conductas descritas en el artículo 578 del Código Penal suponen «no sólo un refuerzo y apoyo a actuaciones criminales muy graves y a la sostenibilidad y perdurabilidad de las mismas, sino también otra manifestación muy notoria de cómo por vías diversas generará el terror colectivo para hacer avanzar los fines terroristas ${ }^{52}$ ". En este sentido, como recuerda la STC 136/1999, de 20 de julio, "el terrorismo constituye una manifestación delictiva de especial gravedad, que pretende instaurar el terror en la sociedad y alterar el orden constitucional democrático, por lo que ha de admitirse que cualquier acto de apoyo al mismo comporta una lesión, al menos potencial para bienes jurídicos individuales y colectivos de enorme entidad ${ }^{53}$ ".

En tercer lugar, se examinará la compatibilidad del artículo 578 del Código Penal con el principio de proporcionalidad que, a su vez, se compone de tres subprincipios, que son: el de adecuación, necesidad y proporcionalidad en sentido estricto.

Así, respecto de la idoneidad de la medida parece claro que a priori esta limitación puede contribuir a evitar la emisión de mensajes que justifiquen el uso de la violencia para conseguir objetivos de carácter político. Del mismo modo, la vía penal es apta para conseguir un mayor grado de ejercicio de los derechos fundamentales reconocidos en la Constitución, pues evita el efecto de desaliento en su ejercicio por parte de las potenciales víctimas de los actos terroristas alabados o justificados.

En relación con la necesidad de la medida de control, como afirma la doctrina y la propia exposición de motivos de la ley ${ }^{54}$, este artículo tiene como objetivo sancionar una serie de conductas que eran muy di-

dad sea implícita con lo que no se plantean dificultades para poder deducir dicha finalidad de la intención objetiva o subjetiva del poder legislativo. (...) En el caso de no plasmación de la medida el Tribunal Constitucional, como órgano encargado del examen de su constitucionalidad, debe intentar deducir la motivación del legislador». Véase GAVARA DE CARA, J.C.: "El principio de proporcionalidad como elemento de control de las restricciones de los derechos fundamentales", Repertorio Aranzadi del Tribunal Constitucional, núm. 16, 2003, p. 19.

52 Véase exposición de motivos de la LO 7/2000, de 22 de diciembre.

53 Véase STC 136/1999, de 20 de julio, FJ 27. ${ }^{\circ}$. En este sentido, véase el voto particular formulado por Don Rafael de Mendizábal Allende. Asimismo sobre el concepto jurídico de terrorismo, entre otros, véase ASÚA BATARRITA, A.: "Concepto jurídico de terrorismo y elementos subjetivos de finalidad. Fines políticos últimos y fines de terror instrumental» en ECHANO BALADÚA J.I. (Coord.): Estudios jurídicos en memoria de José María Lidón, Universidad de Deusto, Bilbao, 2002, p. 41 y ss.

${ }^{54}$ Véase CAMPO MORENO, J.C.: "El enaltecimiento o justificación de los delitos terroristas o de sus miembros", La Ley, núm. 5332, 2001, p. 1752. 
fíciles de perseguir como apología del terrorismo ya que el artículo 18 del Código Penal sólo considera la apología del delito como forma de provocación y por su naturaleza y circunstancias constituye una incitación directa al delito ${ }^{55}$. Asimismo se considera que no es evidente que exista otro tipo de medida alternativa menos gravosa para dar alcance a la finalidad perseguida, dado que es muy difícil imaginar que este tipo de mensajes que conviven con el terrorismo se puedan evitar, por ejemplo, acudiendo a la vía civil ${ }^{56}$.

Respecto al principio de proporcionalidad en sentido estricto, se considera que la cuantía de la pena que establece el artículo 578 no es excesiva en comparación con la entidad del delito, por varias razones:

En primer lugar, en la STC 136/1999, de 20 de julio, dictada en un caso que, salvando las distancias, podría ser penalizado de acuerdo al delito estudiado, la pena mínima era de seis años. De acuerdo con el artículo 578 del actual Código penal, la pena será de uno a dos años de prisión, lo que en ninguno de los casos parece desmesurado dados los efectos que tienen este tipo de mensajes en el ejercicio de los derechos fundamentales $y$, por ende, en el funcionamiento del sistema democrático. Del mismo modo, si comparamos las penas con otros delitos que se cometen con motivo del ejercicio de las libertades de expresión e información como, por ejemplo, el delito de calumnia con publicidad que se castiga con la pena de prisión de seis meses a dos años (el artículo 578 prescribe la pena de uno a dos años), no parece excesivamente desproporcionada teniendo en cuenta la importancia de los derechos y valores constitucionales protegidos por el Código Penal en ambos artículos.

En segundo lugar, si se ponderan las ventajas e inconvenientes del sacrificio impuesto por la intervención estatal, las expresiones que se describen en el tipo en nada tienden a la formación de la opinión pública, sino más bien todo lo contrario, pues, precisamente procuran

${ }^{55}$ En este sentido, la definición que el artículo 18 del Código Penal da de la apología del delito es muy similar a la establecida por el Tribunal Supremo norteamericano. Concretamente, en la sentencia United States v. Ohio, (395 U.S. 444 1969) el aludido Tribunal afirmó que: "las garantías constitucionales de la libre expresión y prensa no permiten al Estado prohibir o proscribir la defensa del uso de la fuerza o la violación de la ley excepto cuando esta defensa va dirigida a incitar o producir una acción ilícita inminente y es probable que se produzca esta acción".

${ }^{56}$ En este sentido, se debe recordar el reducido alcance del Tribunal Constitucional respecto a la existencia de medidas alternativas menos gravosas. Sobre la cuestión, entre otras, véanse STC 161/1997, de 2 de octubre, FJ 11. ${ }^{\circ}$ y STC 136/1999, de 20 de julio, FJ 28. ${ }^{\circ}$. 
lanzar públicamente mensajes que pretenden promocionar los métodos terroristas de una banda armada y a la organización en sí misma. Por el contrario, las ventajas que se derivan de esta medida son muchas para varios bienes constitucionales. Este tipo de restricción tiende a proteger el libre y efectivo ejercicio de las libertades públicas como las de expresión o de participación política de los ciudadanos en general, y de la clase política en particular, sin ningún tipo de injerencia o amenaza velada por parte de terceros. Además, también preserva el normal funcionamiento de las instituciones democráticas. Así, cabe preguntarse, ¿realmente pueden los ciudadanos ejercer su libertad de expresión y participar libremente en el debate público en una sociedad en la que parte de sus miembros justifican o amparan las acciones terroristas contra otro sector de sus miembros?; ¿el acceso al mercado de las ideas se realiza de una manera efectivamente libre por todos y de la misma manera?; ¿un ciudadano o un político se expresará de la misma manera en un clima como el descrito?. Se pondrán algunos ejemplos para exponer la idea que se pretende mantener. Imagínese un pleno de un ayuntamiento en el que tras un atentado terrorista contra un miembro de un partido político representado en ese ayuntamiento, un concejal se manifiesta desde el punto de vista de elogio o exaltación hacia la citada acción. ¿Alguien considera sinceramente que los demás concejales se expresarán con la misma libertad? O, por el contrario, se producirá un efecto de desaliento o silenciador por miedo a sufrir las mismas acciones. ¿Verdaderamente la formación de la voluntad del citado órgano se producirá de manera totalmente libre? Otro supuesto, supóngase el caso de otro ayuntamiento que en un clima de violencia terrorista nombra hijo predilecto a un terrorista $y$, junto a varios vecinos, le homenajean públicamente. Los ciudadanos que no coincidan con los citados planteamientos, ¿podrán presentarse a las elecciones de ese municipio con la misma libertad que en el caso de no haberse celebrado impunemente el citado homenaje? ¿Verdaderamente se forma la opinión pública con la citada expresión colectiva?; o, por el contrario, ¿tiende a realizar una acción dañina? Lamentablemente los casos expuestos no son inventados ${ }^{57}$. Parece claro que las aludidas expresiones no cumplen con la dimensión institucional de la libertad de expresión, no se fomenta el debate público, sino que se restringe de manera clara. El funcionamiento del libre mercado de las ideas, la libre formación de la opinión pública o la libre formación de la voluntad de las instituciones representativas, en definitiva, la propia dinámica del sistema democrático, se resienten. Por

${ }^{57}$ A modo de ejemplo, véase STSJPV de 31 de marzo de 2004. 
todo ello, se mantiene que es necesario que el Estado limite los citados discursos de acuerdo con los requisitos formales y materiales anteriormente estudiados.

En el otro lado de la balanza se encuentra el posible efecto disuasorio o chilling effect que la limitación que se establece en el artículo 578 del Código Penal puede generar en el ejercicio de la libertad de expresión ${ }^{58}$. Sobre esta cuestión, hay que tener en cuenta que existen otros delitos que se cometen con motivo del ejercicio de la libertad de expresión como, por ejemplo, las injurias, que también podrían tener un efecto de desaliento en la citada libertad. Precisamente eso es lo que se pretende disuadir, que nadie que lesione el honor o la dignidad de la persona permanezca impune. Como afirma BILBAO UBILLOS en un contexto similar, "cuesta aceptar la existencia de este efecto disuasorio, de autocensura, en los sectores que justifican la violencia de ETA cuando en los muros y las calles del País Vasco se jalean impunemente las hazañas bélicas de esta organización y las declaraciones de los dirigentes abertzales no ocultan sus simpatías por su macabra ejecutoria ${ }^{59}$ ".

Por último, el artículo 578 del Código Penal tampoco vulnera el contenido esencial de la libertad de expresión. De ningún modo este precepto penal vulnera aquella parte del contenido del derecho que permite a su titular realizar los intereses para cuya satisfacción se le otorga el derecho, porque no se le priva de participar en la libre formación de la opinión pública, sólo se le impide que emita cualquier tipo de mensajes que contengan claras connotaciones intimidatorias $y$, por tanto, son susceptibles de limitar la libertad de opción de los ciudadanos. Partiendo de la delimitación del contenido esencial empleada por VIVES ANTÓN, que se corresponde con el derecho a discrepar razona-

58 Sobre la doctrina del efecto de desaliento en la jurisprudencia del Tribunal Constitucional, entre otras, véanse STC 78/1995, STC 79/1995 y STC 190/1996.

59 Posteriormente este autor añade: «En la sociedad vasca (también en la navarra) se registra sin duda un efecto de desaliento, pero de signo contrario. Me refiero a los miles de vascos (y de navarros) amordazados que no ejercen su derecho a la libertad de expresión (...) por la implacable amenaza de ETA. La sentencia parece olvidar el efecto desmovilizador de la impunidad para el libre ejercicio de los derechos. Pienso en el desánimo que produce la sensación de que son los cómplices de los verdugos los que disfrutan realmente de sus libertades, mientras que las víctimas están atemorizadas". (El texto entre paréntesis es mío). Véase BILBAO UBILLOS, J.M.: "La excarcelación tenía un precio: el Tribunal enmienda la plana al legislador (Comentario de la STC 136/1999, en el caso de la Mesa Nacional de HB)", Revista Española de Derecho Constitucional, núm. 58, 2000, p. 323 y ss. 
damente ${ }^{60}$, parece que este tipo de argumentos no aportan razones o defienden pacíficamente las ideas, sino que introducen en el libre mercado de las ideas mensajes que buscan perturbar la paz o generalizar el miedo, en definitiva, tratan de que el debate democrático no se ejerza en libertad.

En virtud de los argumentos expuestos, cabe concluir que el artículo 578 del Código penal se adecua a la Constitución. En cualquier caso, en el momento de su aplicación, se deberá realizar una ponderación que atienda a las circunstancias del caso concreto, como el contexto en el que se realizan, la gravedad de las manifestaciones o el posible efecto silenciador o de intimidación en la ciudadanía. En la citada ponderación cobra especial relevancia que las conductas expresivas descritas en el artículo 578 del Código Penal tengan lugar uen un contexto de actividad terrorista o simplemente, favorable o predispuesto a la violencia, y cuando las manifestaciones objeto de restricción sean capaces de provocar especial impacto, haciendo temer el incremento de disturbios ${ }^{61} »$.

\subsection{La libertad de expresión y la ilegalización de los partidos políticos}

La mayoría de la doctrina ha planteado numerosas objeciones en relación con la constitucionalidad de la LOPP ${ }^{62}$. Sin embargo, como se ha

\footnotetext{
${ }^{60}$ Véase VIVES ANTÓN, T.S.: La libertad como pretexto, ob. cit., p. 371.

${ }^{61}$ Véase el voto particular formulado por JIMÉNEZ DE PARGA a la STC 136/1999, de 20 de julio.

Por otro lado, BERNAL DEL CASTILLO considera que dada la problemática del artículo 578 del Código Penal, se debería considerar que éste tipificaría el enaltecimiento o la justificación del terrorismo, cuando de dichas conductas se derive un riesgo genérico, indirecto o circunstancial, apto para la creación o el favorecimiento de un clima social del terrorismo, sin que sea necesario que constituya una provocación directa a delitos concretos o personas determinadas. Véase BERNAL DEL CASTILLO, J.: «Observaciones en torno a la Ley Orgánica 7/2000, de modificación del Código Penal en materia de terrorismo", ob. cit., p. 1629.

62 Entre otras cuestiones y, sin ánimo de exhaustividad, la doctrina critica la LOPP porque establece un procedimiento preferente y no penal para proceder a la disolución de un partido. Además se le achaca que es una ley ad casum o de caso único, configurada estructuralmente bajo el contenido de una ley especial. También se tacha su carácter fragmentario, dado que, de un lado, omite cuestiones tan importantes como la financiación de los partidos políticos, y de otro, no regula suficientemente cuestiones como, por ejemplo, los derechos de los afiliados. Asimismo se plantean dudas de constitucionalidad sobre la imposibilidad para determinados condenados no rehabilitados de constituir partidos políticos.
} 
enunciado, el presente estudio sólo se centrará en la posible vulneración de la libertad de expresión ${ }^{63}$.

El artículo 9.1 de la LOPP, después de señalar que los partidos políticos ejercerán libremente sus actividades, entre las que obviamente se incluye la libertad de expresar su oferta programática, añade que "deberán respetar en las mismas los valores constitucionales, expresados en los principios democráticos y en los derechos humanos". Posteriormente, en su apartado segundo determina que "un partido político será considerado ilegal cuando su actividad vulnere los principios democráticos, particularmente cuando con la misma se persiga deteriorar o destruir el régimen de libertades o imposibilitar o eliminar el sistema democrático ${ }^{64} »$. A partir de esta primera definición de las actividades o conductas contrarias a los valores constitucionales, el artículo 9.2 de la LOPP expone las conductas que, de realizarse de manera reiterada y grave, determinarán la ilegalización de un partido políti$\mathrm{co}^{65}$. Posteriormente, en el número 3 del mismo artículo, se concretan las circunstancias del apartado segundo que, en relación con las libertades de expresión e información se pueden agrupar en los tres siguientes bloques de conductas:

1. Las acciones de apoyo o de exculpación de la violencia o el terrorismo. Así, el artículo 9.3 a) considera que son actividades que vulneran los principios democráticos «dar apoyo político expreso (...) al

63 En este sentido, se debe tener en cuenta que la STC 48/2003, de 12 de marzo, FJ 5. ${ }^{\circ}$, mantiene que la base legal de la LOPP se encuentra: "en los artículos 53.1 y 81.1 CE, en relación con los artículos 20, 22 y 23». Es decir, la actual LOPP también regula cuestiones relacionadas con las libertades de expresión e información.

${ }^{64}$ Como se observa arriba, la LOPP pretende perseguir determinadas conductas de los partidos políticos y no determinados fines o ideas. Sin embargo, se considera que, en la práctica, es muy difícil, por no decir imposible distinguir con total claridad entre los medios y los fines.

${ }^{65}$ Las aludidas actividades son las siguientes: $1 .^{\circ}$. La vulneración de los derechos fundamentales promoviendo, justificando o exculpando los atentados contra la vida o la integridad de las personas, o la exclusión o persecución de personas por razón de su ideología, religión o creencias, nacionalidad, raza, sexo u orientación sexual. 2. ${ }^{\circ}$. El fomento, favorecimiento o legitimación de la violencia para la consecución de objetivos políticos o para hacer desaparecer las condiciones precisas para el ejercicio de la democracia, del pluralismo y de las libertades políticas. $3 .^{\circ}$. El complemento o apoyo político a la acción de organizaciones terroristas para la consecución de sus fines de subvertir el orden constitucional o alterar gravemente la paz pública, tratando de someter a un clima de terror a los poderes públicos, a determinadas personas o grupos de la sociedad o a la población en general, o contribuir a multiplicar los efectos de la violencia terrorista y del miedo y la intimidación generada por la misma. 
terrorismo, legitimando las acciones terroristas para la consecución de fines políticos al margen de los cauces pacíficos y democráticos, o exculpando y minimizando su significado y la violación de derechos fundamentales que comporta». De igual manera, los apartados b) y h) consideran que son actividades antidemocráticas "acompañar la acción de la violencia con programas y actuaciones que fomentan una cultura de enfrentamiento y confrontación civil ligada a la actividad de los terroristas, o que persiguen intimidar, hacer desistir, neutralizar o aislar socialmente a quienes se oponen a la misma, haciéndoles vivir cotidianamente en un ambiente de coacción, miedo, exclusión o privación básica de las libertades y, en particular, de la libertad para opinar y para participar libre y democráticamente en los asuntos públicos" y, la de "promover, dar cobertura o participar en actividades que tengan por objeto recompensar, homenajear o distinguir las acciones terroristas o violentas o a quienes las cometen o colaboran con las mismas». Por último, el apartado d) también considera actividades antidemocráticas, la utilización "como instrumentos de la actividad del partido, juntamente con los propios o en sustitución de los mismos, símbolos, mensajes o elementos que representen o se identifiquen con el terrorismo o la violencia y con las conductas asociadas al mismo".

Varias apreciaciones se pueden hacer sobre este primer bloque. En primer lugar, la enumeración y descripción tan amplia de las conductas se justifica en que las posibilidades expresivas son muy amplias. Además, se pretende enumerar con la mayor amplitud posible las conductas expresivas relacionadas con el terrorismo o la violencia con el fin de evitar su impunidad. En segundo lugar, las conductas enunciadas son parcialmente coincidentes con las descritas en los artículos 510, 578 y 607 del Código Penal que, al menos los dos primeros, en abstracto se ajustan a la Constitución. En tercer lugar, la utilización de simbología terrorista hace referencia al leguaje simbólico. Y, en cuarto lugar, el elemento común de las expresiones citadas es el ejercicio de una coacción de tal magnitud que impide la libre discusión de ideas y, en el ámbito político, el libre contraste de programas.

2. La cesión de las prerrogativas de los partidos políticos a favor de los grupos terroristas o de los grupos que les apoyan ${ }^{66}$. La citada cesión de las prerrogativas de los partidos políticos se refiere al derecho de acceso de los grupos políticos a los medios de comunicación públicos reconocido en el artículo 20.3 de la Constitución, que durante la campaña

${ }^{66}$ Véase artículo 9.3 e) de la LOPP. 
electoral y el periodo de referéndum se concreta en la cesión de espacios electorales gratuitos.

3. También, de manera discutible, se considera que determinadas conductas silenciosas como "dar apoyo político (...) tácito al terrorismo, legitimando las acciones terroristas para la consecución de fines políticos al margen de los cauces pacíficos y democráticos, o exculpando y minimizando su significado y la violación de derechos fundamentales que comporta" pueden determinar la ilegalización de un partido político. Como se observa, mediante este supuesto se sancionaría la libertad de expresión negativa ${ }^{67}$.

Por otro lado, el artículo 9.4 de la LOPP establece que para apreciar y valorar las conductas comunicativas que pueden generar la ilegalización de un partido político, se tendrá en cuenta la actuación de sus dirigentes, representantes en las instituciones democráticas, etc. Asimismo el citado artículo enumera, a título de ejemplo, que se valorarán, entre otras, conductas comunicativas como: los comunicados públicos, el desarrollo de actos públicos, las convocatorias públicas (reuniones, manifestaciones, etc.), las manifestaciones públicas o las propuestas formuladas por sus representantes en las instituciones ${ }^{68}$.

Pues bien, una vez descritas las actuaciones comunicativas que pueden generar la ilegalización de un partido político, se tratará de determinar su idoneidad constitucional de acuerdo con los tres parámetros enunciados con anterioridad.

Así, en primer lugar, se analizará la LOPP desde la dimensión institucional de las libertades de expresión e información. Al igual que se

${ }^{67}$ Sobre las citadas conductas comunicativas, se debe tener en cuenta que, como advierte la STC 48/2003, de 12 de marzo, FJ 10. ${ }^{\circ}$, "la interpretación sistemática (...) de todo el artículo en el que se incardinan obliga a entender que en las conductas descritas en el número 3 del artículo 9 han de concurrir los rasgos genéricos a que se refiere el número 2 del mismo precepto. Las conductas enumeradas en el artículo 9.3 LOPP no son sino una especificación o concreción de los supuestos básicos de ilegalización que, en términos genéricos, enuncia el artículo 9.2 de la propia Ley; de tal manera que la interpretación y aplicación individualizada de tales conductas no puede realizarse sino con vinculación a los referidos supuestos contenidos en el artículo 9.2».

${ }^{68}$ En este sentido, como afirma ULRICH PIEPER, «pocas veces justificarán los partidos políticos abiertamente el recurso a la violencia en sus programas políticos. Mas bien —según demuestra la experiencia- la violencia se verá justificada indirectamente, en las declaraciones o mensajes individuales de sus portavoces o mediante el apoyo a grupos que recurren a ella o la amparan". Véase ULRICH PIEPER, S.: "Partidos políticos y apología de la violencia», ob cit., p. 288. 
mantuvo respecto del artículo 578 del Código Penal, las expresiones que se sancionan en la LOPP no fomentan la libre discusión de ideas ni contribuyen a la formación de la opinión pública. Sino más bien todo lo contrario. Como afirma VÍRGALA FORURIA, las actividades descritas en el artículo 9 de la LOPP «no pueden ser toleradas por un Estado democrático ya que si se realizan de forma reiterada y grave, como exige la ley, permiten que el propio Estado democrático deje de serlo al ir concediendo a un partido la posibilidad de ejercer un grado de coacción tal que impide el libre contraste de opiniones y programas ${ }^{69}$. En parecido sentido, la STS de 27 de marzo, dictada en aplicación de la LOPP, mantiene que: "la actuación de los partidos políticos demandados, llevada a efecto por sus militantes o responsables, ha producido en la realidad social una situación de enfrentamiento y de hostigamiento sistemático a los ciudadanos que no profesan sus ideas, que se ha traducido en una verdadera asfixia de su derecho de participación política y de libre expresión y defensa de sus opiniones ${ }^{70}$ ". Con el objeto de no incurrir en reiteraciones se remite a todo lo afirmado precedentemente.

En segundo lugar, para el análisis de la LOPP se partirá de la jurisprudencia del TEDH, dado que este tribunal ha concretado los criterios de limitación de la libertad de asociación como consecuencia de las conductas comunicativas del sustrato social de los partidos políticos ${ }^{71}$. Más en concreto, el aludido Tribunal afirma que "en tanto en cuando sus actividades participan de un ejercicio colectivo de la libertad de expresión, los partidos políticos pueden invocar la protección de los artículos 10 y 11 del Convenio ${ }^{72}$ ». Dicho con otras palabras, el TEDH a la hora de enjuiciar la ilegalización de los partidos políticos sobre la base del derecho de asociación del artículo 11 del Convenio, "recuerda que, a pesar de su papel autónomo y de la especificidad de la esfera de su aplicación, el artículo 11 debe ser también contemplando a la luz del artículo 10. La protección de las opiniones y la libertad de expresarlas

${ }^{69}$ Véase VÍRGALA FORURIA, E.: "Los partidos políticos tras la LO 6/2002», Teoría y Realidad Constitucional, núms. 10-11, 2. ${ }^{\circ}$ semestre 2002-1 1. er semestre 2003, p. 251.

70 Véase STS de 27 de marzo, FJ 6..

71 Véase, entre otras, STEDH de 30 de enero de 1998, "caso Partido Comunista Unificado de Turquía», STEDH de 25 de mayo de 1998, "caso partido socialista de Turquía", STEDH de 8 de diciembre de 1999, "caso Partido de la libertad y de la democracia", STEDH de 31 de julio 2001, "caso Partido de la Prosperidad", STEDH de 7 de febrero de 2002, "caso E.K», STEDH de 9 de abril de 2002, "caso Partido del Trabajo del pueblo (HEP)».

72 Véase STEDH de 30 de enero de 1998, "caso Partido Comunista Unificado de Turquía», párr. 43. 
constituye uno de los objetivos de la libertad de reunión y de asociación que consagra el artículo 11. Lo es todavía más en el caso de los partidos políticos, teniendo en cuenta su papel esencial para el mantenimiento del pluralismo y el buen funcionamiento de la democracia ${ }^{73}$ ".

Como cuestión previa, se destacará que para el TEDH los partidos políticos desempeñan un papel esencial en el mantenimiento del pluralismo y del buen funcionamiento del sistema democrático. Por lo tanto, las excepciones contempladas en el artículo 11 del CEDH requieren de una interpretación estricta, sólo razones convincentes podrán justificar restricciones a libertad de asociación ${ }^{74}$. $Y$ esto se justifica en que "una formación política no puede verse hostigada por el solo hecho de querer debatir públicamente la suerte de una parte de la población de un Estado e implicarse en la vida política de éste a fin de encontrar, dentro del respeto a las reglas democráticas, soluciones que puedan satisfacer a todos las partes afectadas ${ }^{75}$ " .

Según el TEDH, un partido puede auspiciar el cambio de las estructuras legales o constitucionales de un Estado con dos condiciones: en primer lugar, los medios utilizados a tal fin deben ser desde todos los puntos de vista legales y democráticos. Y, en segundo lugar, la modificación propuesta debe ser en sí misma compatible con las reglas básicas de la democracia sobre la que se asienta el propio Convenio ${ }^{76}$.

\footnotetext{
${ }^{73}$ Véase, entre otras, STEDH de 25 de mayo de 1998, "caso Partido Socialista de Turquía", párr. 41, STEDH de 9 de abril de 2002, "caso Yazar», párr. 46.

${ }^{74}$ Véase STEDH de 25 de mayo de 1998, "caso Partido Socialista de Turquía", párr. 50.

${ }^{75}$ Véase STEDH de 30 de enero de 1998, "caso Partido Comunista Unificado de Turquía", párr. 57. Asimismo, entre otras, véanse STEDH de 25 de mayo de 1998, "caso Partido Socialista de Turquía", párr. 45, STEDH de 31 de julio 2001, "caso Partido de la Prosperidad", párr. 45, STEDH de 10 de diciembre de 2002, "caso DEP», párr. 45.

${ }^{76}$ Dicho en palabras del propio tribunal, "un partido político puede hacer campaña a favor de un cambio de la legislación o de las estructuras legales o constitucionales del Estado con dos condiciones: 1) los medios utilizados a este efecto deben ser desde todo punto de vista legales y democráticos; 2) el cambio propuesto debe ser él mismo compatible con los principios democráticos fundamentales. De ello se deriva necesariamente que un partido político cuyos responsables incitan a recurrir a la violencia o proponen un proyecto político que no respeta una o varias normas de la democracia o que tiende a la destrucción de ésta así como al desconocimiento de los derechos y libertades que ésta reconoce, no puede prevalerse de la protección del Convenio contra las sanciones impuestas por estos motivos. Véanse, entre otras, STEDH de 31 de julio de 2001, "caso Partido de la Prosperidad", párr. 46, STEDH de 9 de abril de 2002, "caso Partido del Trabajo del Pueblo (HEP)", párr. 49, STEDH de 10 de diciembre de 2002, "caso DEP», párr. 46.
} 
Como se observa, un partido político puede ser ilegalizado cuando en sus actividades utilice métodos violentos, entre los que se incluye la incitación o justificación de la violencia o del terrorismo. Y en el supuesto de que pretenda la consecución de fines incompatibles con el modelo de democracia establecido en el CEDH. Esto lleva a la conclusión de que la jurisprudencia del TEDH confirma los dos modelos de democracia que poseen los Estados firmantes del CEDH, el de democracia procedimental, en el que estaría incluido España, por el que se trata de impedir la utilización de medios antidemocráticos para conseguir fines políticos. Y, el de democracia militante, cuyo paradigma es Alemania, por el que están vedados constitucionalmente determinados objetivos políticos y, con ello, se impide la realización de proyectos políticos que tienden a la destrucción de la democracia o el desconocimiento de las libertades públicas que ésta reconoce ${ }^{77}$.

Dado que el Tribunal Constitucional ha declarado que el ordenamiento constitucional español no alberga un concepto de democracia militante $^{78}$, el presente estudio sólo se centrará en aquellos otros aspectos de la jurisprudencia del TEDH que analizan las conductas comunicativas de los partidos políticos y de sus dirigentes que pueden generar la ilegalización de los mismos. Así, el citado tribunal, una vez constatada la existencia de las conductas comunicativas enunciadas, y tras apreciar que la injerencia estaba prevista en la ley y se justifica en la consecución de alguno de los fines legítimos establecidos en el Convenio; tratará de determinar la necesidad de la restricción "para una sociedad democrática" lo que le obligará a examinar la proporcionalidad de la medida ateniéndose a las circunstancias que rodean al caso sometido a examen. Respecto de esta última cuestión, el TEDH podrá tomar en cuenta los estatutos y el programa político del partido

${ }^{77}$ Sobre el modelo de democracia militante o beligerante, entre otros, véanse, FALLER J.H.: «Defensa constitucional por medio de la jurisdicción constitucional en la República Federal de Alemania», Revista de Estudios Políticos, núm. 7, 1979, p. 47 y ss, HINAREJOS PARGA, A.: "La prohibición de partidos políticos como mecanismo de defensa del Estado", Teoría y Realidad Constitucional, núms. 10-11, $2 .^{\circ}$ semestre 2002-1er semestre 2003, p. 269 y ss, IÑIGUEZ, D. y SABINE, F.: "La prohibición de partidos políticos en Alemania», Claves para la razón práctica, núm. 122, p. 30 y ss, JIMÉNA QUESADA, L.: "La posición constitucional de Alemania en el contexto europeo: la revisión del concepto "democracia militante»", Cuadernos de la Cátedra Fadrique Furió Ceriol, núms. 14/15, 1996, p. 191 y ss, SÁNCHEZ GONZÁLEZ S.: La libertad de expresión, Marcial Pons, Madrid, 1992, p. 99 y ss, VON BEYME, K.: "La protección del ordenamiento constitucional alemán y del sistema democrático en Alemania", Revista de Estudios Políticos, núm. 35, 1983, p. 73 y ss.

78 Véase STC 48/2003, de 12 de marzo, FJ 7.․ 
disuelto ${ }^{79}$, así como sus actividades, entre las que se incluirán las declaraciones públicas de sus dirigentes o representantes en los medios de comunicación, mítines, reuniones de partido, instituciones representativas, etc. ${ }^{80}$.

EI TEDH sigue básicamente el mismo criterio que en el caso de que las declaraciones fueran realizadas por un ciudadano o incluso un político. Por tanto, comprueba si las declaraciones pueden considerarse como una incitación o justificación del recurso a la fuerza con fines políticos ${ }^{81}$. Así, por ejemplo, en la STEDH de 31 de julio 2001, "caso Partido de la Prosperidad", se determina que la llamada a la Yihad como método político por parte de los dirigentes de un partido político es una causa de ilegalización del mismo ${ }^{82}$. Por el contrario, en la STEDH de 9 de abril de 2002, "caso Partido del Trabajo del Pueblo (HEP)", determinó que el HEP no expresaba ningún apoyo o aprobación explícita del uso de la violencia como método político. Asimismo el TEDH exige para valorar la proporcionalidad de la medida, esto es, de la ilegalización, que las acciones descritas se realicen de manera reiterada. En consecuencia, la STEDH de 10 de diciembre de 2002, "caso DEP", tras considerar demostrado que el ex presidente del DEP aprobó el recurso a la violencia como método político y realizó un llamamiento a hacerlo, consideró que era lícita su sanción penal ${ }^{83}$. Posteriormente determinó que este único motivo realizado de manera aislada y por un solo representante del partido no podía justificar una sanción tan general como la disolución de todo un partido político y, por tanto, la medida era desproporcionada a los fines perseguidos.

En resumen, de la jurisprudencia del TEDH se deduce que es lícito establecer una legislación que pueda determinar la ilegalización de un partido político que intente modificar el ordenamiento jurídico por me-

79 Sobre la cuestión téngase en cuenta que, como advierte la STEDH de 30 de enero de 1998, "caso Partido Comunista Unificado de Turquía», párr. 58, "no puede descartarse que el programa político de un partido esconda objetivos e intenciones diferentes de los que pregona públicamente. Para asegurarse de ello, es preciso comparar el contenido de dicho programa con los actos y tomas de postura de su titular».

80 Véase STEDH de 31 de julio 2001, "caso Partido de la Prosperidad", párr. 79.

81 Véase STEDH de 25 de mayo de 1998, "caso partido Socialista de Turquía", párr. 46, STEDH de 9 de abril de 2002, "caso Partido del Trabajo del Pueblo (HEP)", párr. 55 y 60.

${ }^{82}$ La Yihad consiste en la guerra santa y la lucha a realizar hasta llegar al dominio total de la religión musulmana en la sociedad.

${ }^{83}$ Véase STEDH de 10 de diciembre de 2002, "caso DEP», párr. 62 y ss.

(C) UNED. Revista de Derecho Político 
dios violentos. En cualquier caso, y en relación con las libertades de expresión e información, el TEDH realizará una ponderación de las circunstancias del caso que, como consecuencia de la severidad de la posible ilegalización de un partido político, se exigirá que las expresiones que inciten o amparen el terrorismo se realicen de manera reiterada y grave, no siendo suficientes declaraciones aisladas. Esta postura también se ha adoptado en la LOPP, probablemente por referencia a la jurisprudencia analizada, ya que exige que las conductas que pueden llevar a la ilegalización de un partido político se hayan realizado de forma continuada, reiterada y grave ${ }^{84}$.

Por último, se abordará la cuestión desde la teoría general de la limitación de los derechos fundamentales en la Constitución española. Como es obvio, la libertad de actuación de los partidos no es absoluta, sino que está limitada por la libertad de los demás partidos y del resto de los ciudadanos, así como por los bienes constitucionalmente protegidos. En relación a los bienes constitucionalmente protegidos por la LOPP, la exposición de la misma establece que "el objetivo es garantizar el funcionamiento del sistema democrático y de las libertades esenciales de los ciudadanos, impidiendo que un partido político pueda, de forma reiterada y grave, (...) apoyar políticamente la violencia y las actividades de bandas terroristas". Parece desprenderse que el legislador limita la libertad de expresión de los partidos políticos para la defensa o salvaguardia del funcionamiento del Estado democrático y del pluralismo político, del ejercicio de los derechos fundamentales que le son inherentes y la protección de la paz social. En este sentido, como afirma DÍEZ-PICAZO, la LOPP no permite la represión de cualquier expresión de odio, sino sólo las que afecten al fair play político ${ }^{85}$.

Una vez analizados los bienes jurídicos protegidos, se tratará de determinar la proporcionalidad de la limitación de la libertad de expresión de los partidos políticos. Dicho con otras palabras, se analizará si las restricciones cumplen con el triple test que establece el principio de proporcionalidad. Así, en primer lugar, parece claro que se está ante una medida idónea que a priori es apta para lograr la protección de los principios democráticos y los derechos fundamentales. Mediante esta restricción se puede disuadir a los partidos políticos de emitir expresiones de incitación o amparo del terrorismo, que cedan sus prerroga-

${ }^{84}$ Véase artículo 10.2 b) de la LOPP y STC 48/2003, de 12 de marzo, FJ 12. .

${ }^{85}$ Véase DÍEZ-PICAZO, L.M.: "Sobre la constitucionalidad de la ley orgánica de partidos políticos", Repertorio Aranzadi del Tribunal Constitucional, núm. 15, 2002, p. 6. 
tivas derivadas de su libertad de expresión, esto es, su acceso a los medios de comunicación públicos durante los procesos electorales para emitir mensajes que traten de condicionar la libre elección de los ciudadanos. Además, se está ante una medida que fomenta que la confrontación y discusión de los programas políticos se realice de manera libre y, por ende, mediante procedimientos democráticos.

En relación con la necesidad de la limitación, no sólo la medida es necesaria en una sociedad democrática, sino que precisamente pretende preservar una sociedad democrática. Así, el Tribunal Constitucional considera que la LOPP cumple con el citado requisito, fundamentalmente por dos razones. De un lado, "la existencia de un partido político que con su actividad colabore o apoye la violencia terrorista, pone en peligro la subsistencia del sistema pluralista proclamado por la Constitución; y frente a ese peligro, no parece que pueda aplicarse otra sanción reparadora del orden jurídico perturbado que la disolución $^{86}$ ". De otro, considera que "no es constitucionalmente rechazable que un partido que con su actuación ataca al pluralismo, poniendo en peligro total o parcialmente la subsistencia del orden democrático, incurra en causa de disolución ${ }^{87}$ ".

Opinión matizada merece la necesidad de introducir entre el elenco de supuestos de ilegalización el caso del apoyo tácito al terrorismo. Parece muy difícil interpretar que la mera negativa, por ejemplo, a condenar una atentado terrorista sin realizar ningún acto como minimizarlo o ampararlo pueda conducir a una situación de riesgo ${ }^{88}$. Aunque pueden darse casos de apoyo implícito al terrorismo mediante, por ejemplo, la declaración de día de fiesta local el día de un atentado terrorista o dedicar el nombre de una calle a un terrorista condenado reiteradamente ${ }^{89}$. En este sentido, el Tribunal Constitucional ha afirmado que, sin que corresponda ahora "determinar si la mera ausencia de condena puede ser o no entendida como apoyo implícito al terrorismo, lo cierto es que la legitimación de las acciones terroristas o la exculpación o minimización de su significado antidemocrático y de la violación de derechos fundamentales que comportan puede llevarse a cabo de modo implícito, mediante actos concluyentes, en determinadas cir-

${ }^{86}$ Véase STC 48/2003, de 12 de marzo, FJ 12..

87 Véase STC 48/2003, de 12 de marzo, FJ 12..

${ }^{88}$ En sentido similar, véase VÍRGALA FORURIA, E.: "Los límites constitucionales a los partidos políticos en la LO 6/2002», ob. cit., p. 64.

${ }^{89}$ Véase TORRES DEL MORAL, A.: "La inconstitucionalidad de los partidos políticos. A propósito de la Ley Orgánica 6/2002, de partidos políticos", ob. cit., p. 60. 
cunstancias, siendo claro que, en tales supuestos, no puede hablarse de vulneración de la libertad de expresión ${ }^{90} »$. A pesar de lo dicho por el Alto Tribunal, probablemente hubiera sido mejor suprimir el apoyo tácito al terrorismo de la LOPP dado que los demás supuestos son suficientes para dar eficacia a la ley ${ }^{91}$.

Respecto al principio de proporcionalidad en sentido estricto, que se corresponde con la ponderación de las ventajas e inconvenientes de la medida limitadora del derecho fundamental, como ya se dijo en el epígrafe anterior, la emisión de los mensajes que se sancionan en nada favorecen o fomentan el libre contraste de programas e ideas entre distintos partidos políticos ni tampoco tienden a formar la opinión pública. Por el contrario, pretenden socavar la dinámica del sistema democrático, precisamente se sancionan con el objeto de preservar el propio sistema democrático y el pluralismo político que le es inherente. De igual manera, la sanción impuesta, esto es, la disolución del partido político, tampoco parece desproporcionada, dado que la LOPP establece claramente que las conductas deberán realizarse de manera reiterada y grave. En consecuencia, cumple con los requisitos establecidos con la jurisprudencia del TEDH que impiden que se ilegalice un partido político como consecuencia de las conductas comunicativas aisladas de los dirigentes o representantes de un partido político ${ }^{92}$. También este es el criterio seguido por el Tribunal Constitucional, dado que la STC 48/2003, de 12 de marzo, recuerda que «ninguna de las descritas en el artículo 9 determina aisladamente la disolución: para que esta pueda tener lugar, es preciso que sean realizadas de forma reiterada y grave como precisa el encabezamiento del artículo $9.2^{93}$ ".

En el otro lado de la balanza, se encuentra el posible efecto de desaliento que puedan generar las sanciones impuestas en la LOPP en el desarrollo de las actividades o conductas de los partidos políticos. En mi opinión, las conductas descritas en la LOPP en nada desalientan las actividades de los partidos políticos salvo, claro está, que se quieran realizar en convivencia con el terrorismo que supone la negación de los derechos fundamentales y del sistema democrático.

90 Véase STC 48/2003, de 12 de marzo, FJ 10. ${ }^{\circ}$. Asimismo véase STC 4/2004, de 16 de enero, FJ $11 .^{\circ}$ y $18 .^{\circ}$.

${ }^{91}$ En este sentido, entre otros, véase TAJADURA TEJADA, J.: Partidos políticos y Constitución: Un estudio de la LO 6/2000 de 27 de junio, de partidos políticos, y de la STC 48/2003, de 12 de marzo, Civitas, Madrid, 2004, p. 115.

92 Véase STEDH de 10 de diciembre de 2002, "caso DEP», párr. 62 y ss.

${ }^{93}$ Véase STC 48/2003, de 12 de marzo, FJ 12.. 
Por último, las conductas comunicativas sancionadas en la LOPP tampoco vulneran el contenido esencial de la libertad de expresión. No desnaturalizan ni hacen impracticable el derecho fundamental. La libertad de expresión no pierde en ninguno de los modos su importancia para la vida social, dado que, precisamente, este tipo de expresiones no cumplen con la función social o institucional que cumplen en el Estado social y democrático de Derecho. Si se acude de nuevo a la definición del contenido esencial de la libertad de expresión dada por VIVES ANTÓN, que se corresponde con el derecho a discrepar razonadamente; las expresiones sancionadas no aportan razones, sino elementos de intimidación que tienen como consecuencia un importante efecto de desaliento en el ejercicio de los derechos de participación y de la libertad de expresión de los demás ciudadanos con lo que se falsea el funcionamiento del sistema democrático.

En resumen, con las matizaciones realizadas en relación con el apoyo tácito al terrorismo, se considera que la regulación establecida en al LOPP no vulnera, al menos en abstracto, la libertad de expresión reconocida en la Constitución. En cualquier caso, en el momento de su aplicación, el juez deberá resolver el conflicto entre la libertad de expresión y su restricción teniendo en cuenta las circunstancias concretas del caso como, por ejemplo, el contexto en que se realizan las manifestaciones, la efectiva existencia de la utilización de la violencia como método político, la gravedad de las manifestaciones o su posible efecto silenciador.

\section{RESUMEN}

Las libertades de expresión y de información desempeñan un papel fundamental en el funcionamiento de las modernas democracias occidentales. Sin embargo, las citadas libertades públicas, como el resto de derechos fundamentales reconocidos en la Constitución, se encuentran sometidas a limitaciones derivadas del reconocimiento de otros derechos o bienes constitucionales.

El presente artículo tiene por objeto analizar la legitimidad constitucional de la limitación de los discursos públicos que justifican el uso de la violencia para la consecución de fines políticos. En España, las citadas restricciones se regulan en el artículo 578 del Código Penal, introducido mediante la LO 7/2000, de 22 de diciembre, por el que se castiga la justificación pública o enaltecimiento del terrorismo y la LO 6/2002 de Partidos Políticos, por la que cabe la posibilidad de proceder a la ilegalización de los partidos políticos cuyos dirigentes, representantes públicos, etc., realicen manifestaciones públicas de similares características. 
Para realizar la labor descrita se ha acudido fundamentalmente a tres criterios o parámetros distintos, que son: la dimensión objetiva o institucional de las libertades de comunicación pública reconocida en la jurisprudencia del Tribunal Constitucional, la jurisprudencia del Tribunal Europeo de los Derechos Humanos y la teoría general de la limitación de los derechos fundamentales en el ordenamiento constitucional español.

\title{
Palabras clave
} rismo.

Libertad de expresión, límites a los derechos fundamentales, terro-

\section{Title}

Freedom of expression, terrorism and limits of the fundamental rights.

\begin{abstract}
Freedom of expression and Freedom of communication play a fundamental role in contemporany western democracies. However, these public freedoms, as the rest of recognized fundamental rights by the Spanish Constitution, are subdued to limitations which are linked to other constitutional rights and goods recognition.

This article has the objective of analyzing the constitutional legitimacy of political speeches' limits that justify the use of violence to achieve political goals. In Spain, such restrictions are regulated by the 578 Criminal Code Article, introduced by LO 7/2000 on December 22nd that punishes public justification of terrorism, and LO 6/2002 known as Political Parties Act that recognizes the possibility to proclaim illegal a political party if their leaders, representative members and so on show in public those ideas.

To fulfill this work, three distinct fundamental criteria had being used, such as the objective dimension of communication's freedom recognized by the Spanish Constitutional Court, European Court of Human Rights' Case Law and general theory of fundamental rights' limits of Spanish Constitutional rules.
\end{abstract}

\section{Key words}

Freedom of expression, terrorism, limits of the fundamental rights. 